\title{
The Danish National Chronic Lymphocytic Leukemia Registry
}

This article was published in the following Dove Press journal:

Clinical Epidemiology

25 October 2016

Number of times this article has been viewed

\section{Caspar da Cunha-Bang' \\ Christian Hartmann Geisler ${ }^{2}$ \\ Lisbeth Enggaard ${ }^{3}$ \\ Christian Bjørn Poulsen ${ }^{4}$ \\ Peter de Nully Brown ${ }^{2}$ \\ Henrik Frederiksen ${ }^{5}$ \\ Olav Jonas Bergmann 6 \\ Elisa Jacobsen Pulczynski ${ }^{7}$ \\ Robert Schou Pedersen ${ }^{8}$ \\ Linda Højberg Nielsen ${ }^{9}$ \\ Ilse Christiansen ${ }^{10}$ \\ Carsten Utoft Niemann ${ }^{2}$}

'Department of Internal Medicine, Roskilde Hospital, Roskilde, Denmark;

${ }^{2}$ Department of Hematology,

Rigshospitalet, Copenhagen University

Hospital, Copenhagen, Denmark;

${ }^{3}$ Department of Hematology, Herlev

Hospital, Herlev, Denmark; ${ }^{4}$ Department

of Hematology, Roskilde Hospital,

Roskilde, Denmark; ${ }^{5}$ Department of

Hematology, Odense University Hospital,

Odense, Denmark; 'Department of

Hematology, Vejle Hospital, Vejle,

Denmark; ' ${ }^{7}$ epartment of Hematology,

Aarhus University Hospital, Aarhus,

Denmark; ${ }^{8}$ Department of Hematology,

Holstebro Hospital, Holstebro,

Denmark; ' Department of Hematology,

Esbjerg Hospital, Esbjerg, Denmark

${ }^{10}$ Department of Hematology, Aalborg

University Hospital, Aalborg, Denmark

Correspondence: Carsten Utoft Niemann Department of Hematology, Rigshospitalet, Copenhagen University Hospital,

Building 4042, Blegdamsvej 9, DK-2100

Copenhagen $\varnothing$, Denmark

Tel +45 35457830

$\mathrm{Fax}+4535454772$

Email carsten.utoft.niemann@regionh.dk
Aim: In 2008, the Danish National Chronic Lymphocytic Leukemia Registry was founded within the Danish National Hematology Database. The primary aim of the registry is to assure quality of diagnosis and care of patients with chronic lymphocytic leukemia (CLL) in Denmark. Secondarily, to evaluate adherence to national guidelines and to provide source data for research purposes.

Study population: All patients diagnosed with CLL in Denmark from 2008 onward are included in the registry. Patients are followed in one of nine hematology centers. All centers participate in the registry and are all obliged to collect data.

Main variables: Predefined data are collected at the time of diagnosis, and follow-up at the time of significant events: treatment, progression, transplantation, and death. Parameters included in the International Workshop on Chronic Lymphocytic Leukaemia criteria for diagnosis, and for decision on treatment initiation as well as characteristics included in the CLL International Prognostic Index are collected.

Descriptive data: To ensure full coverage of Danish CLL patients in the registry, both continuous queries in case of missing data, and cross-referencing with the Danish National Patient Registry are performed. Data from the registry are published in an annual report summarizing the collected data, the overall survival for yearly cohorts, and the degree of data coverage. Per year approximately 450 new patients with CLL are registered in the registry, cumulative as of July 1, 2015, 3,082 patients have been registered.

Conclusion: The Danish National CLL Registry is based within the Danish National Hematology Database. The registry covers a cohort of all patients diagnosed with CLL in Denmark since 2008. It forms the basis for quality assessment of CLL treatment in Denmark and offers a unique opportunity for population-based research.

Keywords: CLL, population based, epidemiology, targeted treatment, survival, comorbidity

\section{Background}

In Denmark, a number of regional and national quality databases, based on individual patient data, have been established. The Danish National Hematology Database was founded in 2005 by a fusion of The Danish National Lymphoma Registry, The Danish National Acute Leukemia Registry, and The Danish National Myeloma Database. In 2008, The Danish National Chronic Lymphocytic Leukemia Registry was founded within the Danish National Hematology Database. The overall purpose of the registry is to assure high quality patient care and diagnostics for patients with chronic lymphocytic leukemia (CLL) in Denmark, to assess adherence to national guidelines for CLL, and to provide source data for research purposes. The Danish National CLL Registry submit your manuscript | www.dovepress.com

Dovepress

http://dx.doi.org/10.2147/CLEP.S99486
Clinical Epidemiology 2016:8 56I-565 (Thematic series on clinical quality databases in Denmark) 56 I (c) (1) (5) $\odot 216 \mathrm{da}$ Cunha-Bang et al. This work is published and licensed by Dove Medical Press Limited. The full terms of this license are available at https://www.dovepress. cc. the work you hereby accept the Terms. Non-commercial uses of the work are permitted without any further permission from Dove Medical Press Limited, provided the work is properly attributed. For permission for commercial use of this work, please see paragraphs 4.2 and 5 of our Terms (https://www.dovepress.com/terms.php). 
is approved by the National Board of Health. Based on the Danish legislation, these nationwide registries are exempt from the requirement to achieve informed consent from the individual patients enrolled. If the data are subsequently used for research purposes, approval from the Data Protection Agency or the ethics committee system is required, depending on the project.

\section{Study population}

All patients diagnosed with CLL in Denmark from 2008 onward are included in the registry. Per year approximately 450 new patients with CLL are registered in the registry, cumulative as of July 1, 2015, 3,082 patients have been registered, no retrospective registration of patients diagnosed prior to 2008 has been performed. All patients are initially followed in one of nine hematology centers in Denmark (see Figure 1 for data flowchart). Patients needing treatment and close monitoring are continuously followed in one of the centers, a minority of patients with low risk disease are followed by their general practitioner after initial diagnosis at one of the hematology centers. All nine centers participate in the registry and are obliged to collect data on all newly diagnosed patients with CLL. The registry is owned by the Danish Regions (five local government entities), ${ }^{1}$ with centralized data management through the Danish Multidisciplinary Cancer Groups. ${ }^{2}$ The database is supported by the Registry Support Centre of Epidemiology and Biostatistics (East) and the Registry Support Centre of Clinical Quality and Health Informatics (East).

\section{Main variables}

A range of predefined variables are collected at the time of diagnosis. These include baseline demographic characteristics, prognostic markers, clinical stage, World Health Organization performance status, ${ }^{3}$ and patient-reported symptoms. Dates and results of prognostic tests and events are registered to allow for follow-up over time at the individual patient level (Table 1). Continuous collection of follow-up data in the registry is carried out according to a predefined range of variables at the time of significant events: treatment, progression, transplantation or death. All variables included in the International Workshop on Chronic Lymphocytic Leukaemia (IWCLL) criteria $^{4}$ for diagnosis and treatment initiation as well as the characteristics included in the International Prognostic Index for Patients with CLL (CLL-IPI) 5 are included in the registry (Table 1).

\section{Information on administrative issues}

Funding for the Danish National CLL Registry within the Danish National Hematology Database is achieved through a yearly application to the Danish Regions' Database Funds for The Danish Clinical Registries, ${ }^{1}$ which is funded by the Danish Regions. The Danish health system is also supported

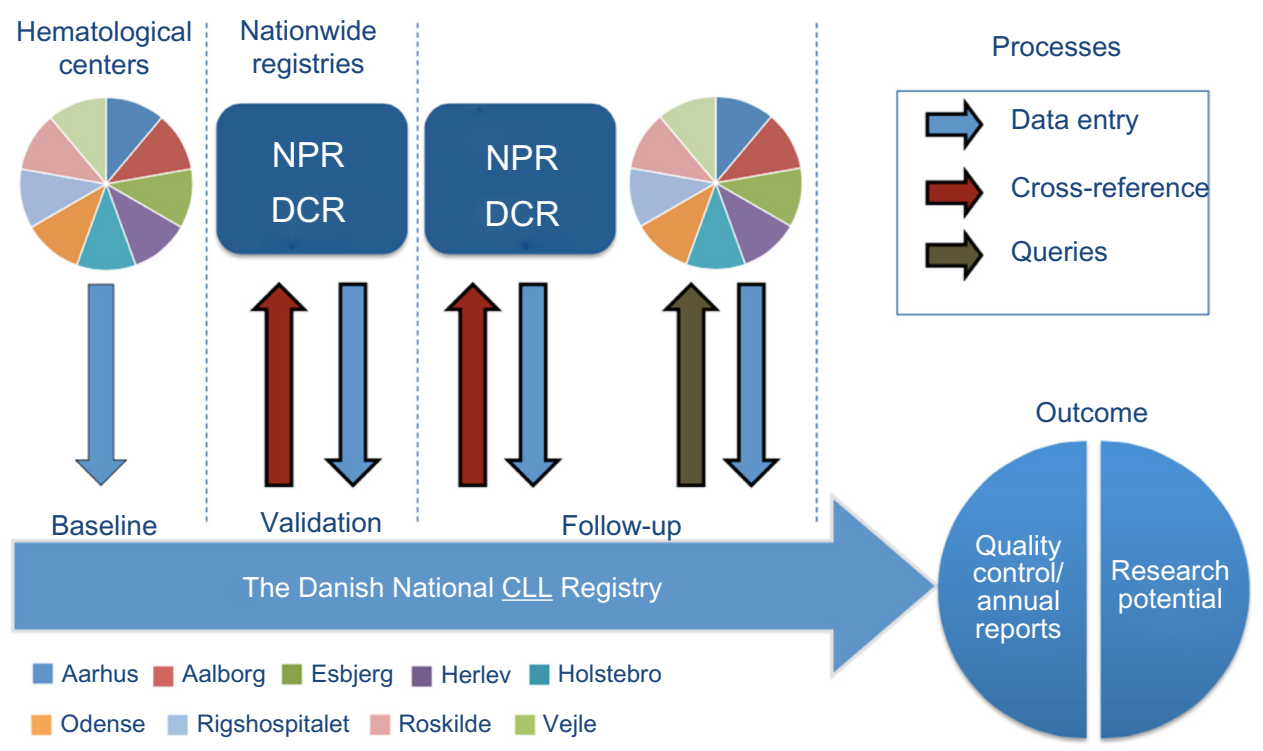

Figure I Data flowchart.

Notes: Dataflow in The Danish National CLL Registry. At the time of diagnosis, baseline registration is performed at one of nine centers. Data are validated through crossreferencing with The National Patient Registry (NPR) and The Danish Cancer Registry (DCR). Data describing follow-up variables are continuously registered at the time of significant events. These data form the basis for quality assessment of treatment for patients with CLL in Denmark and offers a unique opportunity for population-based research.

Abbreviation: CLL, chronic lymphocytic leukemia. 
Table I Main variables

\begin{tabular}{|c|c|c|}
\hline Variable name & $\begin{array}{l}\text { Baseline (B) } \\
\text { Follow-up (F) }\end{array}$ & $\begin{array}{l}\text { IWCLL (I) } \\
\text { CLL-IPI } \\
\text { (C) }\end{array}$ \\
\hline \multicolumn{3}{|l|}{ Demographics } \\
\hline ID & $\mathrm{B}$ & \\
\hline Sex & B & \\
\hline Date of birth & $\mathrm{B}$ & \\
\hline Age & $\mathrm{B}$ & $\mathrm{C}$ \\
\hline Family history of CLL & B & \\
\hline Date of diagnostic test & B & \\
\hline \multicolumn{3}{|l|}{ Diagnostics and results } \\
\hline Bone marrow biopsy & B & \\
\hline Absolute lymphocyte count & $\mathrm{B}$ & I \\
\hline Flow cytometry & $\mathrm{B}$ & 1 \\
\hline $\begin{array}{l}\text { FISH (del I Iq, trisomy I2, del I3qI4, } \\
\text { del I7p) }\end{array}$ & B & I, C \\
\hline IGHV mutational status & B & $\mathrm{I}, \mathrm{C}$ \\
\hline Imaging & B & \\
\hline \multicolumn{3}{|l|}{ Symptoms and clinical observations } \\
\hline Weight loss (>10\%/6 months) & B & \\
\hline Fever of unknown origin ( $>2$ weeks) & B & \\
\hline Fatigue & B & \\
\hline Night sweat & B & \\
\hline Performance status WHO & $\mathrm{B}$ & \\
\hline Binet/Rai & $\mathrm{B}$ & I, C \\
\hline \multicolumn{3}{|l|}{ Prognostic tests and results } \\
\hline IGHV mutational status ( $\geq 98 \%)$ & B & \\
\hline ZAP 70 & B & \\
\hline CD38 positive & B & \\
\hline Beta 2 microglobulin $>340 \mathrm{nmol} />4 \mathrm{mg}$ & B & C \\
\hline Lymphocyte doubling time $<12$ months & B & \\
\hline $\begin{array}{l}\text { Anemia }(\mathrm{Hb}<6.2 \mathrm{mmol} / \mathrm{L}) / \\
\text { thrombocytopenia }(<100 \mathrm{mia} / \mathrm{L})\end{array}$ & B & \\
\hline $\begin{array}{l}\text { Massive-progressive lymphadenopathy/ } \\
\text { splenomegaly }\end{array}$ & B & \\
\hline Increasing lymphocytosis (>50\%/2 months) & B & \\
\hline $\begin{array}{l}\text { Rapid lymphocyte doubling time } \\
\text { ( }<6 \text { months) }\end{array}$ & B & \\
\hline \multicolumn{3}{|l|}{ Follow-up/treatment } \\
\hline Chemotherapy regimen & $\mathrm{F}$ & \\
\hline Immune therapy & $\mathrm{F}$ & \\
\hline Date of treatment start & $\mathrm{F}$ & \\
\hline Date treatment end & $\mathrm{F}$ & \\
\hline Response & $\mathrm{F}$ & \\
\hline Date of transplantation (if applicable) & $\mathrm{F}$ & \\
\hline MRD analysis performed & $\mathrm{F}$ & \\
\hline Date of progression/relapse & $\mathrm{F}$ & \\
\hline New FISH result (if applicable) & $\mathrm{F}$ & \\
\hline \multicolumn{3}{|l|}{ End of follow-up } \\
\hline Date of death (if applicable) & $\mathrm{F}$ & \\
\hline Cause of death & $\mathrm{F}$ & \\
\hline
\end{tabular}

Notes: Main variables categorized as: demographics, diagnostics and results, symptoms and clinical observations, prognostic tests and results, follow-up/ treatment, and end of follow-up collected in The Danish National CLL Registry. Baseline (B) data are collected at the time of diagnosis and follow-up (F) data are collected continuously at the time of significant events, including progression, treatment, transplantation, and death. Data of variables included in the IWCLL (I) and the CLL-IPI (C) index are collected.

Abbreviations: ID, identification; CLL, chronic lymphocytic leukemia; IWCLL, International Prognostic Index for Patients with CLL; CLL-IPI, Chronic Lymphocytic Leukemia International Prognostic Index; FISH, fluorescence in situ hybridization; IGHV, immunoglobulin heavy chain variable; WHO, World Health Organization; MRD, minimal residual disease.

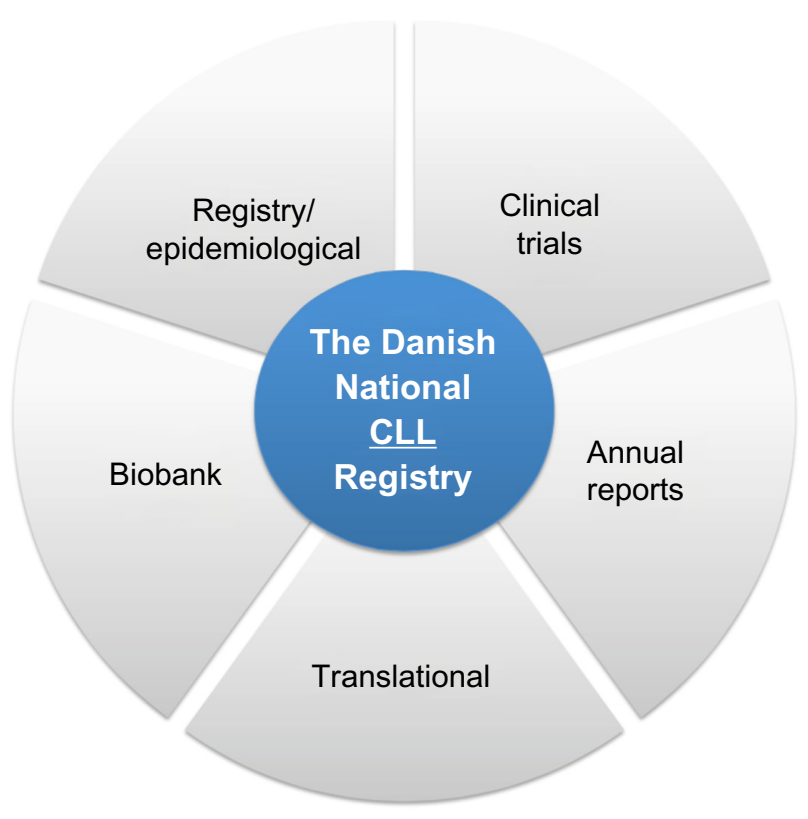

Figure 2 Research strategy/potential.

Notes: The data registered in The Danish National CLL Registry can be used to address research questions at a population-based level through registry-based epidemiological studies, translational research using biobank samples, and by providing easy access to high quality long-term follow-up data for ongoing clinical trials.

Abbreviation: CLL, chronic lymphocytic leukemia.

by a number of nationwide registries; The National Patient Registry, ${ }^{6}$ The Danish Cancer Registry, ${ }^{7}$ the Danish National Pathology Registry and Data Bank, ${ }^{8}$ and the Cause of death register. ${ }^{9}$ To ensure full coverage of the Danish CLL cohort in the Danish National CLL Registry, regular cross-referencing with The National Patient Registry is performed. As this registry forms the economic basis for all hospital departments in Denmark and no patients can be admitted to an inpatient or outpatient specialist clinic in Denmark without being registered, complete coverage of a national cohort of patients with CLL is assured. Additionally, The Danish Cancer Registry and the Danish National Pathology Registry and Data Bank are cross-referenced to assure complete data coverage. The coverage of the registry is reported in yearly reports at lymphoma.dk. For the years 2011-2013, 99\% coverage was achieved; for 2014, 96\% coverage was achieved due to a few cases not yet entered into the database. ${ }^{10}$ The data are validated through the entry process and relevant patients are included in follow-up query lists. To assure high quality of data and consistent follow-up, queries based on crossreferencing with the mentioned registries identify patients who have received treatment for any malignancy or have died since the last follow-up (see Figure 1 for data flowchart). The completeness of data entry for patients receiving treatment is reported in the yearly reports. For the years 2011-2014, 
a completeness of $98 \%, 96 \%, 85 \%$, and $55 \%$ respectively, was achieved. This reflects that despite the cross-referencing setup, some lack of time for data entry is seen.

Data from the Danish National CLL registry are made publicly available through annual reports, ${ }^{10}$ which summarize the collected data, including the overall survival for yearly cohorts of patients with CLL and the degree of data coverage. Also, data for benchmarking of the nine hematology centers in Denmark in terms of data coverage and outcome for patients treated within the different centers are provided. The annual reports form the basis for specific queries on missing data to the nine participating centers to assure data coverage through engaging local data managers at each center.

\section{Examples of research}

The growing understanding of the pathogenesis of CLL including the dependency on micro environmental interactions and the B-cell receptor pathway has led to a paradigm shift in the treatment of patients with CLL. ${ }^{11}$ This rapid development within the translational and clinical research area of CLL warrants epidemiological studies of CLL to increase knowledge of the outcome for patients with CLL treated outside clinical trials. For patients diagnosed with CLL in Denmark within 2011-2014, the 3-year overall survival rate is $82.9 \%$ according to the yearly report. ${ }^{10}$ Currently, pending research issues include but are not limited to: identification of risk factors and genetic factors for CLL; addressing the impact of environmental, social, and lifestyle conditions as well as the impact of comorbidity and treatment-related issues on overall survival over time. ${ }^{12,13}$ Some of these questions can be explored solely by using data from the Danish National CLL Registry.

In another entity, the Danish Cancer Biobank, ${ }^{14}$ local biobanking of tissue, blood, and bone marrow samples from patients diagnosed with cancer are made available for research projects upon approval by the local ethics committee system. Through a combination of data from the Danish National CLL Registry and the Danish Cancer Biobank samples, the potential to incorporate laboratory-based functional and (epi)genetic analyses for correlation with clinical outcomes on a population level can be accomplished. ${ }^{15,16}$ At an even larger scale, international scientific collaborations including merging of cohorts provide the leverage to answer strategic treatment-related questions as well as to achieve the increased power needed to explore rare events and interactions. Also, for ongoing and planned clinical trials, the Danish National CLL Registry assures easy access to complete long-term follow-up data (Figure 2). To this end, the Danish CLL group participates in a number of investigator-initiated trials and collaborate with both the Nordic CLL group (www.nordic-cll.org), the German CLL study group (www.gcllsg.de), and the Hovon Group (www.hovon.nl) in order to coordinate clinical trials.

\section{Conclusion}

The Danish National CLL Registry is based within the Danish National Hematology Database. The registry covers a complete cohort of all patients newly diagnosed with CLL in Denmark since 2008. As of July 1, 2015, 3,082 patients have been included in the CLL registry. It forms the basis for quality assessment of treatment for patients with CLL in Denmark, and offers a unique opportunity for populationbased research projects. Through yearly cross-referencing with other Danish health-related national registries, high quality of data and consistent follow-up is ensured and a multitude of research projects that have hitherto not been possible, are made feasible.

\section{Acknowledgments}

We want to acknowledge all the patients diagnosed with CLL in Denmark, the local data managers at participating centers, the Danish health registries and databases for making this valuable registry possible. This paper was funded by the Program for Clinical Research Infrastructure (PROCRIN) established by the Lundbeck Foundation and the Novo Nordisk Foundation and administered by the Danish Regions.

\section{Disclosure}

Carsten Utoft Niemann is a principal investigator in clinical trials sponsored by Roche (Basel, Switzerland), has received fees for consultancy from Roche, Janssen (NJ, USA), and Gilead (CA, USA), and has received research funding from the Danish Cancer Society. The authors report no other conflicts of interest in this work.

\section{References}

1. The Danish Clinical Registries [homepage on the Internet]. RKKP Denmark; 2015. Available from: http://www.rkkp.dk/in-english/. Accessed March 7, 2016.

2. Danish Multidisciplinary Cancer Groups [homepage on the Internet]. DMCG.DK; 2015. Available from: http://dmcg.dk/en. Accessed March 7, 2016.

3. Oken MM, Creech RH, Tormey DC, et al. Toxicity and response criteria of the Eastern Cooperative Oncology Group. Am J Clin Oncol. 1982;5(6):649-655.

4. Hallek M, Cheson BD, Catovsky D, et al. Guidelines for the diagnosis and treatment of chronic lymphocytic leukemia: a report from the International Workshop on Chronic Lymphocytic Leukemia updating the National Cancer Institute-Working Group 1996 guidelines. Blood. 2008;111(12):5446-5456. 
5. Bahlo J. The International Prognostic Index For Patients With Chronic Lymphocytic Leukaemia (CLL-IPI). ICML; 2015; Lugano. Available from: http://onlinelibrary.wiley.com/doi/10.1002/hon.2227/full.

6. Schmidt M, Schmidt SA, Sandegaard JL, Ehrenstein V, Pedersen L, Sorensen HT. The Danish National Patient Registry: a review of content, data quality, and research potential. Clin Epidemiol. 2015;7: 449-490.

7. Storm HH, Michelsen EV, Clemmensen IH, Pihl J. The Danish Cancer Registry-history, content, quality and use. Dan Med Bull. 1997;44(5):535-539.

8. Erichsen R, Lash TL, Hamilton-Dutoit SJ, Bjerregaard B, Vyberg M, Pedersen L. Existing data sources for clinical epidemiology: the Danish National Pathology Registry and Data Bank. Clin Epidemiol. 2010;2:51-56.

9. Helweg-Larsen K. The Danish Register of Causes of Death. Scand J Public Health. 2011;39(7 Suppl):26-29.

10. Danish Lymphoma Group. Malignant Lymphoma and CLL annual reports 2004-2014. Available from: http://lymphoma.dk/index. php?id=54,0,0,1,0,0. Accessed March 7, 2016.
11. Niemann CU, Jones J, Wiestner A. Towards targeted therapy of chronic lymphocytic leukemia. Adv Exp Med Biol. 2013;792:259-291.

12. Bhayat F, Das-Gupta E, Smith C, McKeever T, Hubbard R. The incidence of and mortality from leukaemias in the UK: a general population-based study. BMC Cancer. 2009;9:252.

13. Kristinsson SY, Dickman PW, Wilson WH, Caporaso N, Bjorkholm M, Landgren O. Improved survival in chronic lymphocytic leukemia in the past decade: a population-based study including 11,179 patients diagnosed between 1973-2003 in Sweden. Haematologica. 2009;94(9):1259-1265.

14. Danish Cancer Biobank [homepage on the Internet]. Available from: http:// www.cancerbiobank.dk. Accessed March 7, 2016.

15. Mounier M, Bossard N, Belot A, et al. Trends in excess mortality in follicular lymphoma at a population level. Eur J Haematol. 2015; 94(2):120-129.

16. Bjorkholm M, Ohm L, Eloranta S, et al. Success story of targeted therapy in chronic myeloid leukemia: a population-based study of patients diagnosed in Sweden from 1973 to 2008. J Clin Oncol. 2011;29(18):2514-2520.
Clinical Epidemiology

\section{Publish your work in this journal}

Clinical Epidemiology is an international, peer-reviewed, open access, online journal focusing on disease and drug epidemiology, identification of risk factors and screening procedures to develop optimal preventative initiatives and programs. Specific topics include: diagnosis, prognosis, treatment, screening, prevention, risk factor modification,

Submit your manuscript here: http://www.dovepress.com/clinical-epidemiology-journa

\section{Dovepress}

systematic reviews, risk \& safety of medical interventions, epidemiology \& biostatistical methods, and evaluation of guidelines, translational medicine, health policies \& economic evaluations. The manuscript management system is completely online and includes a very quick and fair peer-review system, which is all easy to use. 